\title{
Taxol-induced apoptosis in human SKOV3 ovarian and MCF7 breast carcinoma cells is caspase- 3 and caspase- 9 independent
}

\author{
R Ofir ${ }^{1,2,3}$, R Seidman ${ }^{2,3}$, T Rabinski ${ }^{2}$, M Krup $^{2}$, V Yavelsky², \\ $Y$ Weinstein $^{2}$ and M Wolfson ${ }^{\star 2}$ \\ ${ }^{1}$ Department of Research and Development Hazeva, Ben Gurion University of \\ the Negev, Beer Sheva 84105, Israel \\ 2 Department of Microbiology and Immunology, Ben Gurion University of the \\ Negev, Beer Sheva 84105, Israel \\ ${ }^{3}$ Both authors R Ofir and R Seidman, have made equal contribution into this \\ study \\ * Corresponding author: M Wolfson, Department of Microbiology and \\ Immunology, Faculty of the Health Sciences, Ben Gurion University of the \\ Negev, P.0.B. 653, Beer Sheva 84105, Israel Tel: 972-8-6477292; \\ Fax: 972-8-6477626; E-mail: wolfson@bgumail.bgu.ac.il
}

Received 19.6.01; revised 27.11.01; accepted 28.12.01 Edited by B Osborne

\begin{abstract}
Taxol is used in chemotherapy regimens against breast and ovarian cancer. Treatment of tumor model cell lines with taxol induces apoptosis, but exact mechanism is not sufficiently understood. Our results demonstrate that in response to taxol, various cell types differentially utilize distinct apoptotic pathways. Using MCF7 breast carcinoma cells transfected with caspase- 3 gene, we showed that taxol-induced apoptosis occurred in the absence of caspase- 3 and caspase- 9 activation. Similar results were obtained with ovarian SKOV3 carcinoma cells, expressing high level of endogenous caspase-3. In contrast, staurosporine-induced apoptosis in these cells was accompanied by proteolytic cleavage of pro-caspase-3 and induction of caspase-3 enzymatic activity. The effect of taxol appears to be cell type-specific, since taxolinduced apoptosis in leukemia U937 cells involved caspase-3 activation step. We conclude that a unique caspase- 3 and caspase- 9 independent pathway is elicited by taxol to induce apoptosis in human ovarian and breast cancinoma cells.

Cell Death and Differentiation (2002) 9, 636-642. DOI: 10.1038/ sj/cdd/4401012
\end{abstract}

Keywords: ovarian carcinoma; apoptosis; taxol; caspase-3; caspase-9

Abbreviations: Ac-DEVD-CHO, Acetyl-Asp-Glu-Val-Asp-CHO; CAD, caspase-activated Dnase; ICAD, inhibitor of CAD; ICE, interleukin $1 \beta$-converting enzyme; MAPK, mitogen-activated protein kinase; MT, microtubules; PTK, protein tyrosine kinase; STS, staurosporine; TNF, tumor necrosis factor

\section{Introduction}

Taxol (paclitaxel), a potent drug of natural origin isolated from the bark of the Pacific yew Taxus brevifolia, ${ }^{1}$ is currently used in the treatment of breast and ovarian cancer. The efficacy of treating a variety of other human malignancies with taxol is currently being evaluated in clinical trials. ${ }^{2}$ Initial studies on the mechanism of action of taxol have demonstrated that microtubules are the main targets of action. Taxol promotes microtubule (MT) assembly, inhibits MT depolymerization, and changes microtubule dynamics. These effects result in disruption of the normal reorganization of microtubule network required for mitosis and cell proliferation. Taxol-treated cells are unable to proceed normally through the cell cycle, and are arrested in the G2/M phase. ${ }^{3}$

During the last years, additional activities of taxol have been described including the effect on cell signaling and gene expression, activation of mitogenactivated protein kinases (MAPKs), Raf-1 and protein tyrosine kinases (PTK). ${ }^{4,6}$ Treatment of a variety of tumor cells with taxol in vivo and in vitro induces apoptosis, ${ }^{7}$ and it has been shown that the expression of apoptosis-related proteins like bcl-2, bad, bcl-X, p21waf, and tumor necrosis factor 1 (TNF- $\alpha$ ), are regulated by taxol. ${ }^{8-12}$ However, the exact mechanism by which taxol induces apoptosis is unknown.

Apoptotic signaling and execution, involves the activation of caspase proteinases that in turn, cleave key protein substrates (reviewed in ${ }^{13}$ ). On the basis of primary structure, procaspases can be divided into two classes: caspases -2, -8, -9 and 10 which contain long aminoterminal prodomains and act as initiators, and caspase- 3 , -6 and-7 with short prodomains that act as effectors.

Caspase- 3 , the most commonly activated caspase, can stimulate the DNA fragmentation factor, caspase-activated DNase (CAD), by cleaving and inactivating the inhibitor of CAD (ICAD). ${ }^{14,15}$ However, apoptosis can also occur without DNA fragmentation. ${ }^{16,17}$ Studies in vitro have suggested that both cytosolic protein Apaf1 and cytochrome $c$ participate in the caspase-9-dependent activation of caspase-3 to initiate general apoptosis; formation of caspase-9/Apaf-1 complex ${ }^{18-21}$ leads to the processing of pro-caspase-3 and to the activation of caspases-3. ${ }^{21}$ However, as judged by caspase- 3 and caspase- 9 dependency, the results from Casp9 and Casp3 knockout mice lead to the suggestion of four different apoptotic pathways: caspase-9/caspase-3 dependent/independent apoptosis, apoptosis solely dependent on caspase-9 or entirely dependent on caspase- $3 .{ }^{22}$ The fact that several apoptotic pathways coexist in mammalian cells suggests that it is important to reveal the mechanism of apoptosis induced by drugs in cancer therapy. Recent studies demonstrated that $\mathrm{HL}-60$ leukemia cell lines ${ }^{23}$ and non-small cell lung cancer 
cell lines ${ }^{24}$ are susceptible to taxol-induced apoptosis and that caspase- 3 is activated by taxol in these cells. Since breast and ovarian cancer are the main targets of taxol chemotherapy, we decided to study the mechanism of caspase activation following taxol treatment of these types of cancer.

In this study, we investigated the apoptotic pathways utilized by human ovarian and breast cancer cell lines following exposure to taxol. SKOV3 ovarian carcinoma cells represent a model system for ovarian cancer, and MCF7 breast carcinoma cells serve as a model system for breast cancer. Both cell lines are sensitive to taxol. As human MCF7 cells lack functional caspase-3 owing to the $47 \mathrm{bp}$ deletion within the caspase-3 gene, ${ }^{25,26}$ we studied whether taxol induced apoptosis of MCF7 cells transfected with caspase-3 cDNA (MCF7/casp3) will involve the activation of caspase-3.

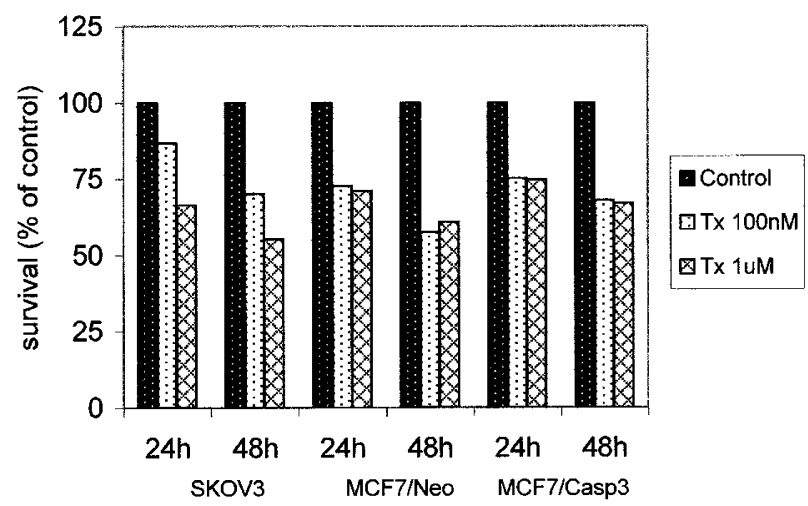

Figure 1 Cytotoxic effect of taxol in ovarian and breast cancer cells. Cytotoxic effect of taxol at the indicated concentrations was measured by the uptake of Neutral Red dye as described in Materials and Methods. Control cells were treated with DMSO $(0.1 \%)$ alone. Results of survival are presented as a per cent of control (DMSO-treated) cells
We assessed caspase-3/-9 activation following taxol treatment of MCF7 cells transfected with caspase-3 cDNA (MCF7/casp3) and SKOV3 cells containing endogenous caspase-3 gene. Our results demonstrate that taxolinduced apoptosis in these cells involves caspase-3 and caspase-9 independent pathways.

\section{Results}

\section{Cytotoxic effects in taxol treated SKOV3 cells and MCF cells}

Treatment of SKOV3 ovarian carcinoma cells with taxol resulted in a $30 \%$ death rate within $48 \mathrm{~h}$ (Figure 1). Similar results (Figure 1) were obtained with MCF7 cells containing the caspase-3 gene (MCF7/Casp3) or the empty vector (MCF7/Neo). As shown in Figure 2, taxol treated MCF7 cells displayed morphological alterations typical of adherent cells undergoing apoptosis, becoming rounded, condensed and detached from the dish. Since MCF7 cells undergo apoptosis despite the fact that the caspase-3 protein is not expressed in these cells, we decided to study whether taxol induced apoptosis involves DNA fragmentation in cells expressing endogenous and transfected caspase-3 gene.

\section{Taxol-induced apoptosis in SKOV3 ovarian carcinoma cells resulted in DNA fragmentation without caspase-3 activation}

Treatment of SKOV3 ovarian carcinoma cells with taxol for 6-24 h resulted in DNA fragmentation. The DNA ladder can already be seen following $12 \mathrm{~h}$ incubation with $100 \mathrm{nM}$ taxol (Figure 3 lane 3). Since taxol induces apoptosis both in caspase-3 deficient cells (MCF7 cells, Figure 2) and caspase3 positive cells (SKOV3 cells, Figure 3 , lanes 3 and 4 ), we assessed the caspase- 3 activity following taxol treatment of the caspase-3 positive SKOV3 cells. As shown in Figure 4A,
A

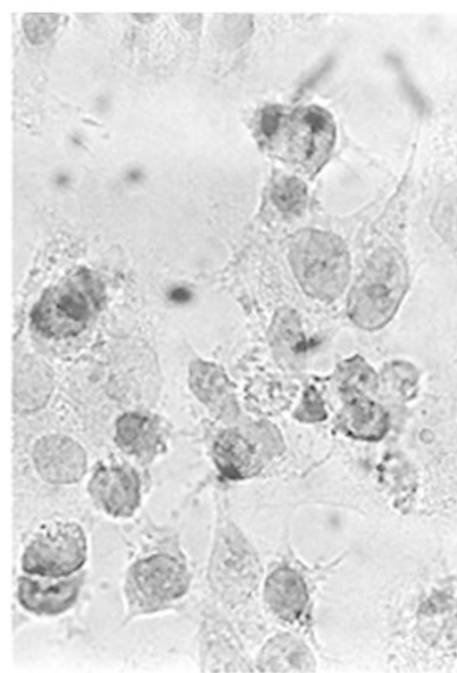

B

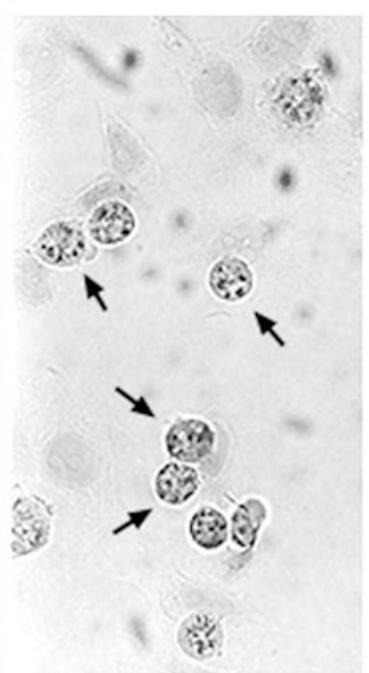

C

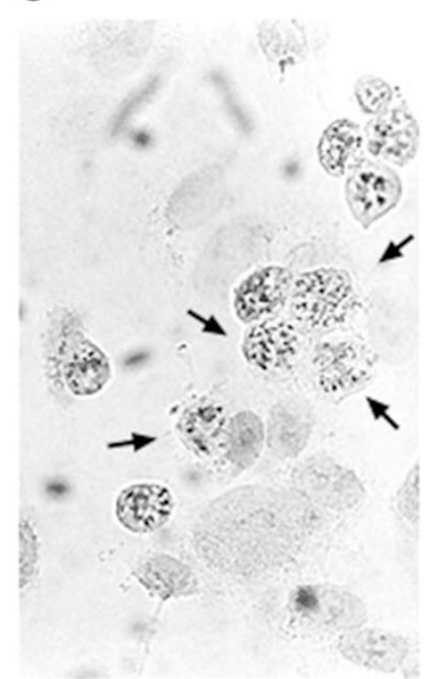

Figure 2 Taxol induces condensation and degradation of chromatin in MCF7 breast cancer cells. (A) Untreated cells, (B) cells treated with $100 \mathrm{nM}$ taxol for $12 \mathrm{~h}$, (C) treatment with $100 \mathrm{nM}$ taxol for $24 \mathrm{~h}$. Arrows indicate condensation (B) and degradation (C) of chromatin 


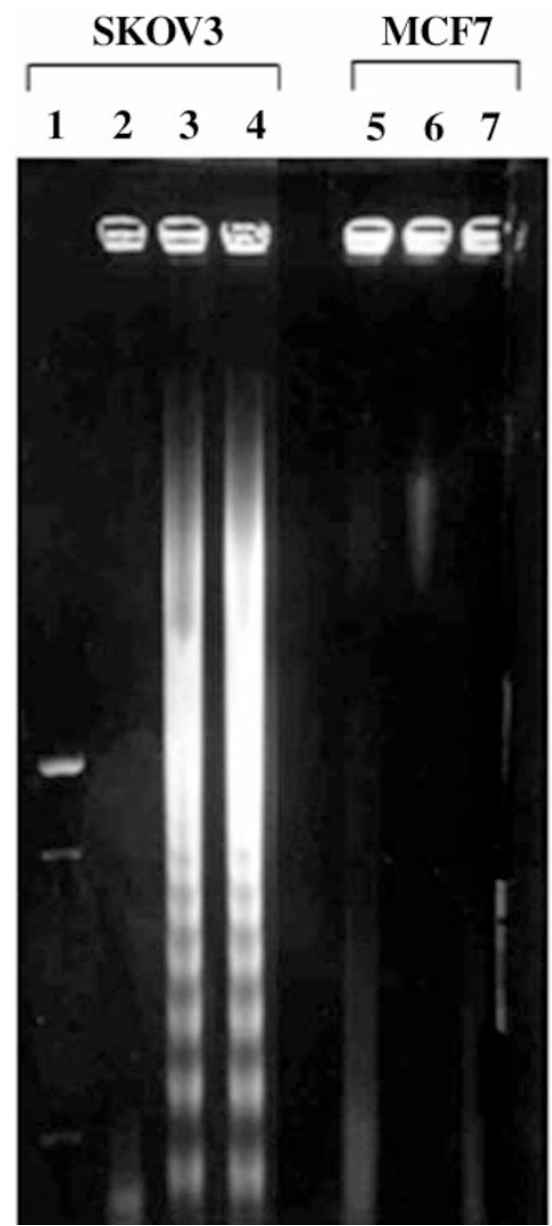

Figure 3 Taxol induces DNA fragmentation in SKOV3 ovarian, but not in MCF7 breast cancer cells. DNA was separated and analyzed on agarose gel as described in Materials and Methods. Lane 1, DNA size marker, lanes 2-4, SKOV 3 cells untreated (lane 2) and treated with $100 \mathrm{nM}$ taxol for 12 and $24 \mathrm{~h}$, lanes 3-4, MCF7 cells untreated (lane 5) and treated with $100 \mathrm{nM}$ taxol for 12 and $24 \mathrm{~h}$, lanes $6-7$

taxol did not induce caspase-3 enzymatic activity in SKOV3 cells whereas incubation with STS resulted in activation of caspase-3 activity. Results from Western blot analysis using anti caspase- 3 antibodies, confirmed that the procaspase- 3 protein was not processed following treatment with taxol whereas STS induced the appearance of the enzymatically active caspase-3 (large subunit, Figure 4B). Therefore, although SKOV3 cells contain endogenous caspase-3 gene and express high levels of caspase- 3 protein, taxol treatment of SKOV3 cells leads to DNA fragmentation without activation of the enzymatic activity of caspase-3.

\section{Taxol does not induce caspase-3 activation and DNA ladder in MCF7/Casp3 cells}

We next studied apoptosis parameters in MCF7 cells containing cDNA of caspase-3 (MCF7/casp3 cells), and compared them to the MCF7 cell transfected with the control vector (MCF7/Neo). MCF7 cells were transfected with caspase-3 in an expression vector (or with a control empty vector), and caspase-3 expression

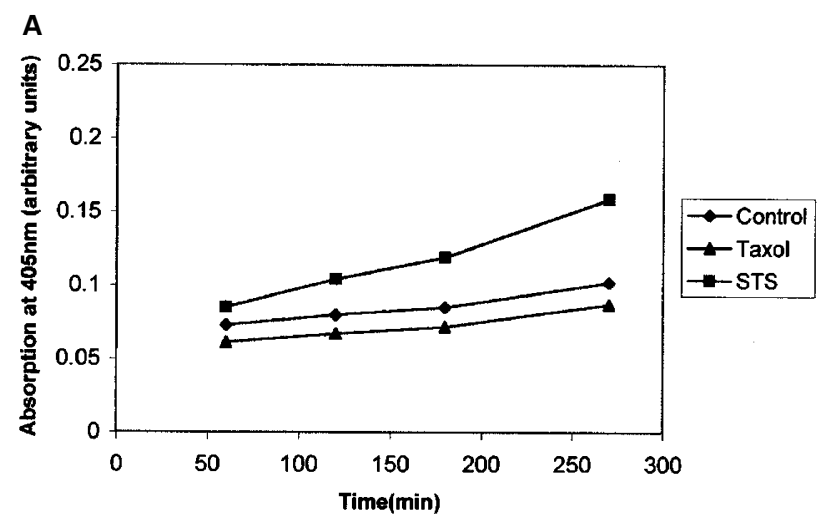

B

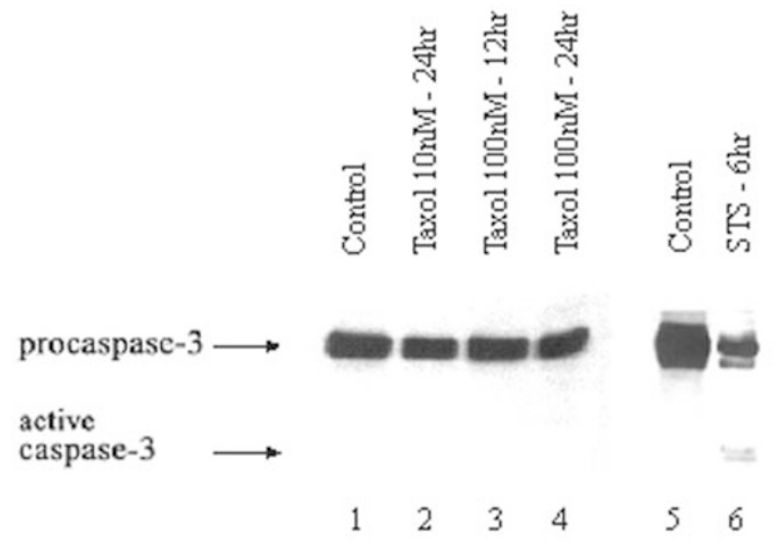

Figure 4 Taxol does not activate caspase-3 in SKOV3 cells. (A) Enzymatic caspase- 3 activity in the cells incubated with $1 \mu \mathrm{M}$ taxol and STS $(1 \mu \mathrm{M})$ for the indicated time intervals. The representative experiment out of four independent experiments is shown. (B) Immunoblotting with antibody recognizing the large subunit of procaspase 3 . Lane 6 , the appearance of the active caspase- 3 in STS-treated cells is seen

was confirmed both in mixed culture of MCF7/Casp3 cell line and in the individual clones. Treatment of MCF7/Casp3 cells with taxol resulted neither in caspase-3 enzymatic activity (Figure 5A), nor in procaspase-3 processing (Figure 5C, lane 5). The caspase-3 pathway in MCF7/Casp3 cells was fully functional as can be demonstrated by treatment with staurosporine (STS), which resulted in efficient induction of caspase-3 enzymatic activity and processing of pro-caspase-3 (Figure 5A,C, lane 4). Treatment of MCF7/Casp3 cells with STS $(1 \mu \mathrm{M})$ for $6 \mathrm{~h}$ resulted in the appearance of the ladder nucleosomal DNA fragments characteristic of apoptosis (Figure 5B). As was shown previously, treatment of MCF7 cells with STS induced apoptosis without DNA fragmentation. ${ }^{25}$ Identical results were obtained using several single cell MCF7/Casp3 clones and a mixed MCF7/ Casp3 cell population. Moreover, incubation of ovarian carcinoma cells derived from ascitic fluids and grown in primary culture did not result in the activation of caspase-3 (Figure 6).

\section{Effect of taxol on caspase-3 activity is cell type specific}

The results presented so far with the two cell lines originated from epithelial tissues and primary ovarian carcinoma cells 
A

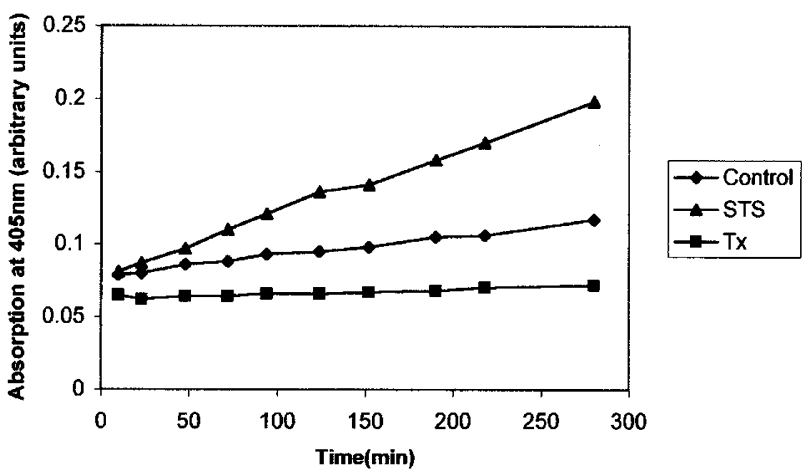

B
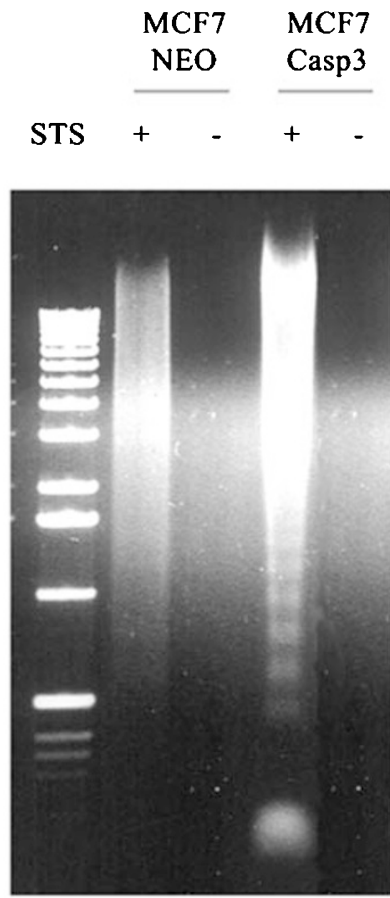

C

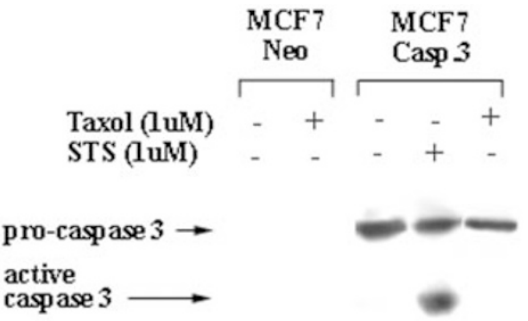

actin

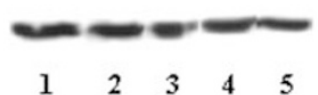

Figure 5 Staurosporine, but not taxol, activates caspase-3 in MCF7/casp3 cells. (A) Enzymatic caspase-3 activity in MCF7/casp3 cells treated with taxol $(1 \mu \mathrm{M}, 24 \mathrm{~h})$ and STS $(1 \mu \mathrm{M}, 6 \mathrm{~h})$ measured as described in Materials and Methods; (B) DNA fragmentation in MCF7/casp-3 cells treated with $1 \mu \mathrm{M} \mathrm{STS}$ for $6 \mathrm{~h}$; (C) Immunoblotting with anti-caspase-3 antibody of total cell lysates prepared from control, taxol-, and STS-treated cells. Immunoblotting with $\beta$ actin shows equal loading of protein on the gel

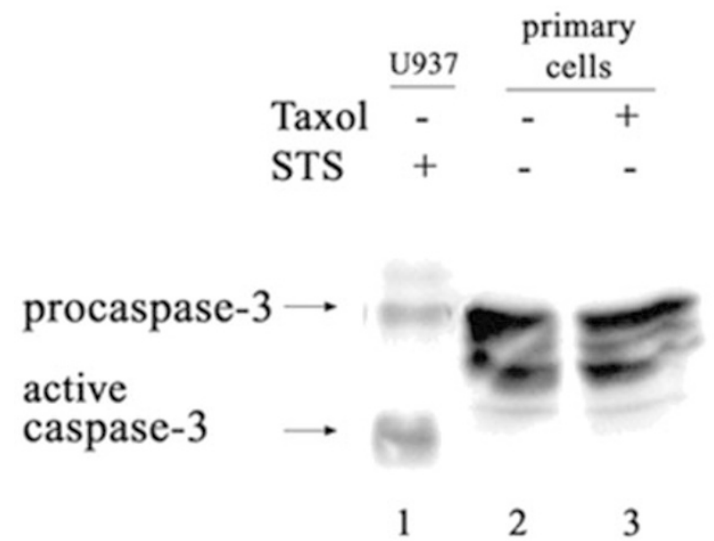

Figure 6 Taxol does not induce procaspase-3 cleavage in primary ovarian carcinoma cells. Primary culture of ovarian carcinoma cells isolated from ascite fluid was treated with $100 \mathrm{nM}$ taxol for $24 \mathrm{~h}$ and analyzed by immunoblotting (lanes 2 and 3). Human leukemia U937 cells treated with STS $(1 \mu \mathrm{M}, 6 \mathrm{~h})$ are shown as a positive control for the assay (lane 1)

indicated that taxol-induced apoptosis, with or without DNA fragmentation, does not involve caspase-3 activation. At this point, we wished to verify whether taxol could lead to caspase-3 activation in a different cell type. An assay of caspase-3 enzymatic activity in U937 leukemic cells showed that taxol treatment induced DEVDase activity that can be inhibited by the specific caspase-3 inhibitor Ac-DEVD-CHO (Figure 7A). Processing of pro-caspase-3 in U937 cells following taxol treatment was confirmed by Western blotting (insert in Figure 7B). Results of caspase-3 activity summarized in Figure 7B, indicate that despite high level of expression of pro-caspase-3 protein in SKOV3 cells, caspase-3 activity following staurosporine treatment is low as compared to U937 and MCF7/Casp3 cells.

\section{Caspase-9 is not processed in taxol-treated SKOV3 and MCF7 cells}

Activation of caspase-9/Apaf1/cytochrome $c$ apoptosome in the non-death receptor-regulated apoptotic pathway leads, in turn, to caspase- 3 activation. Given that caspase- 3 activity is not induced in taxol-treated SKOV3 cells, we reasoned that it might reflect either that caspase-9 is not activated or that an apoptosome is not formed. During activation, Apaf-1-mediated processing of pro-caspase- 9 occurs at Asp 315 to generate the mature caspase- 9 molecule. ${ }^{21}$ To verify whether active caspase- 9 is formed following taxol treatment, the processing of caspase- 9 was examined in taxol-treated SKOV3 cells. Taxol did not induce pro-caspase-9 processing (Figure 8 , lanes $2-4$ ), whereas STS led to procaspase-9 processing and appearance of the active caspase- 9 that can be detected as a $35 \mathrm{kD}$ band (Figure 8, lane 7). Taxol did not induce caspase-9 processing in MCF7 cell as well (Figure 8, lane 9).

\section{Discussion}

Taxol induces apoptosis in a variety of cell types but the exact mechanism of its apoptosis-inducing activity is not sufficiently clear. The results of our study demonstrate a unique mode of 


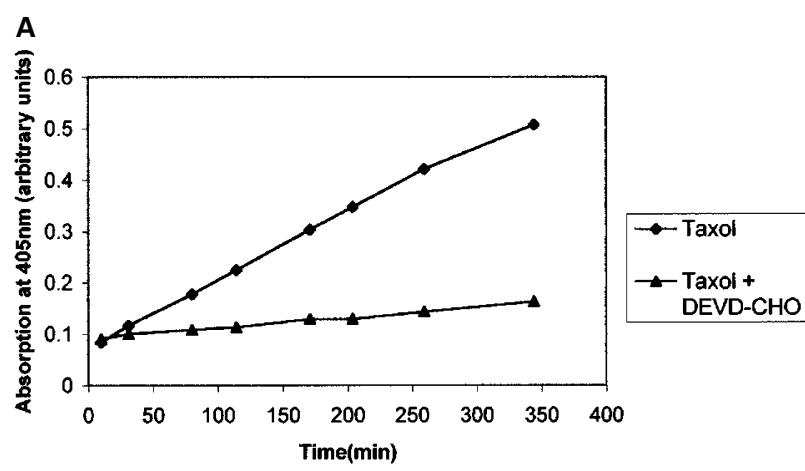

B

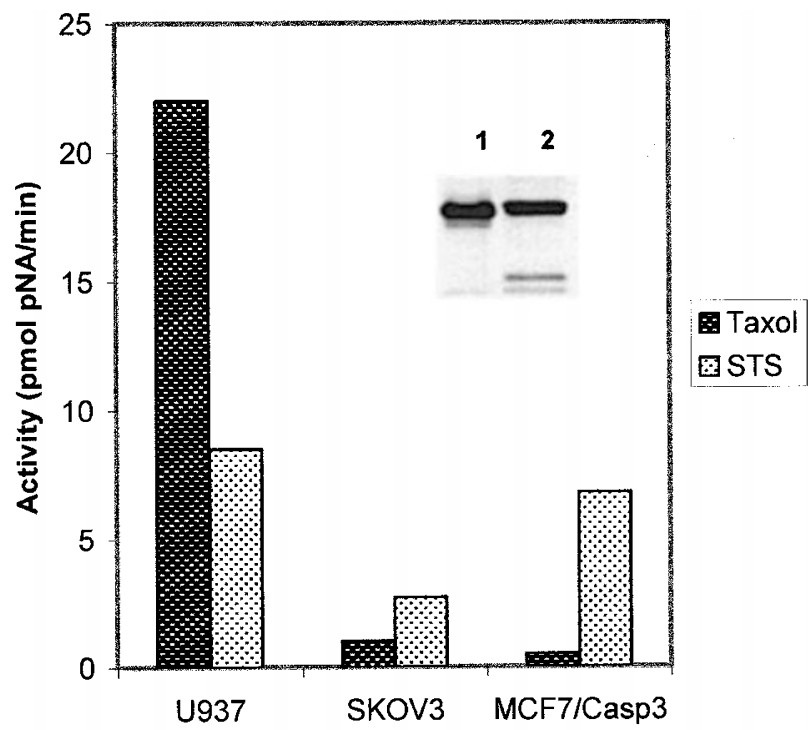

Figure 7 Effect of taxol on caspase-3 activation is cell-type specific. (A) Taxol-induced caspase-3 activity in leukemia U937 cells is inhibited by a specific inhibitor AC-DEVD-CHO. Cellular extracts prepared from the cells incubated with taxol $(1 \mu \mathrm{M})$ and from control cells were used for caspase-3 activity assays. Caspase-3 inhibitor Ac-DEVD-CHO (10 nM) was used to demonstrate the specificity of the assay. (B) Comparison of caspase-3 activation in three cell lines following treatment with taxol and STS. Cells were treated with taxol $(1 \mu \mathrm{M}, 24 \mathrm{~h})$, and STS $(1 \mu \mathrm{M}, 6 \mathrm{~h})$, and caspase- 3 activity was measured as described. Insert: Western blot of caspase-3 processing in U937 cells treated with STS $(1 \mu \mathrm{M}, 6 \mathrm{~h})$. Lane 1 , control untreated and lane 2 , STStreated cells

action of taxol in human breast and ovarian carcinoma cells, which does not require caspase-3 activation. Human MCF7 breast carcinoma cell line represents an excellent model for this study since, due to $47 \mathrm{bp}$ deletion within exon 3 of the caspase-3 gene, these cells do not express functional caspase- 3 protein. ${ }^{26}$ This may explain why taxol induces apoptosis in MCF7 cells without DNA fragmentation (Figures 2 and 3, lanes 6 and 7). The lack of caspase-3 cleavage was not the result of non-functional enzyme in SKOV3 and MCF7 cells, because staurosporine induced caspase-3 activity in these cells. Noteworthy, the caspase-3 activity in SKOV3 cells was only $35-40 \%$ of that of U937 and MCF7/Casp3 cells despite the high levels of caspase-3 protein in SKOV3 cells (Figure 7B).

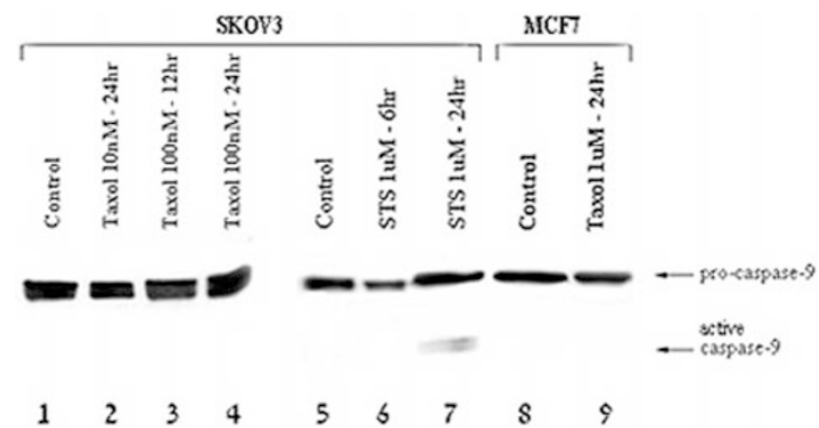

Figure 8 Staurosporine, but not taxol, activates caspase-9 in ovarian SKOV3 cells. Immunoblotting with anti-caspase-9 antibody of total cell lysates prepared from the cells incubated with taxol $(1 \mu \mathrm{M}, 24 \mathrm{~h})$ and STS $(1 \mu \mathrm{M}$, $6 \mathrm{~h})$, as described in Materials and Methods

Our results suggest that the effect of taxol on caspase3 activation is cell type specific because the induction of caspase-3 enzymatic activity was observed in taxoltreated human leukemia U937 cells (Figure 7B). Activation of caspase-3 was also observed during taxol-induced apoptosis in other cell lines including human acute myelocytic leukemia HL-60 cells, ${ }^{23,27}$ human lung cancer cell lines ${ }^{24}$ and human gastric cell lines. ${ }^{28,29}$ These and other results support the notion that different apoptotic pathways may be used by the same apoptotic stimulus in various cells.

Treatment of MCF7 and SKOV3 cells with taxol did not lead to caspase-9 activation (Figure 8, lanes 2-4 and 9). In contrast, staurosporine induced cleavage of procaspase- 9 in SKOV3 cells (Figure 8, lane 7). These results suggest that, although pro-caspase-9 can be processed in SKOV3 cells, it is not activated following taxol treatment. It appears that taxol effect on caspase- 9 activation is also cell type specific. For instance, taxol-induced caspase- 9 cleavage was shown in human leukemic HL-60 cell line. ${ }^{27}$

The pathway utilized by taxol in SKOV3 and MCF7 cells is presently unknown. It may include other caspases, such as caspases-8, -7 or -12 . Recently, it has been reported that incubation with taxol leads to caspase-8 activation in human colon cancer cell line, HT29-D4 ${ }^{28,29}$ and in lung adenocarcinoma cell line,$^{30}$ and it is suggested that this enzyme may be a common mediator of anticancer druginduced apoptosis.

It is also possible that taxol acts via activation of another effector caspase, like caspases- 6 or -7 , or by an unrelated pathway. The possible involvement of caspase-7 in taxolinduced apoptosis in human esophageal squamous cancer cells and in non-small-cell lung cancer H460 and H520 cell lines has been suggested. ${ }^{31,32}$ The existence of a caspase-independent pathway of programmed cell death has been shown genetically. ${ }^{33}$ This pathway depends on apoptosis-inducing factor (AIF), which is localized to mitochondria and released in response to death stimuli. Recently, another calpain has been implicated in promoting caspase-independent apoptosis-like events during platelet activation. ${ }^{34}$ It is thus possible that taxol may utilize AIF or calpain while inducing apoptosis in MCF7 and SKOV3 cells. 
In summary, we have shown that taxol utilizes a unique caspase- 9 and caspase- 3 independent pathway to induce apoptosis in ovarian and breast cancer cells. In addition, our results also demonstrate that the mechanism by which taxol induces apoptosis may be cell type specific, and may be developed with or without DNA laddering. Combination of drugs acting via caspase-3/-9-dependent and -independent pathways may represent a new approach in chemotherapy of cancer.

\section{Materials and Methods}

\section{Materials}

Taxol was obtained from the National Cancer Institute, dissolved in DMSO and stored at $-70^{\circ} \mathrm{C}$. Antibodies against the following proteins were purchased commercially: caspases $-3,-9$ (Pharmingen) and actin (ICN Biomedicals). HRP-conjugated secondary antibodies were from Amersham. All other reagents were purchased from Sigma.

\section{Cell cultures}

Human ovarian SKOV3 and breast MCF7 carcinoma cell lines were grown in MEM-alpha medium and Dulbecco's modified Eagle's medium, respectively, supplemented with $10 \%$ fetal calf serum, $1 \%$ L-glutamine and $1 \%$ penicillin/streptomycin. Human U937 leukemia cells were grown in RPMI 1640 medium with the same supplements. All products for cell cultures were purchased from GIBCO BRL. For primary cultures, tumor cells were isolated from ascitic fluid of ovarian cancer patients, and grown in MEM-alpha medium supplemented with autologous ascitic fluid (30\%). Passages 2-3 were used in the experiments.

\section{Transfections}

The MCF7/neo and MCF/Casp3 cell lines were generated by transfecting MCF7 cells with $20 \mu \mathrm{g}$ pCDNA3.0 and pCDNA3.0/ Caspase3 (pCDNA3/ Caspase 3 was kindly provided by Dr. V Dixit, Melbourne, Australia, pcDNA3 was purchased from Invitrogen) using calcium phosphate. Forty-eight hours post-transfection, cells were

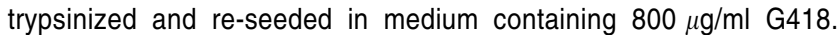
After 4 weeks selection in the G418 medium, single cell clones were selected by limiting dilution. Mixed populations of transfected cells as well as clonal cell lines were used in experiments.

\section{Western blotting}

Cells were lysed with boiling lysis buffer (10 mM Tris- $\mathrm{HCl}, \mathrm{pH} 7.4,1 \%$ SDS) and stored at $-20^{\circ} \mathrm{C}$ or used immediately. Protein concentration was determined by BioRad Protein Detection Reagent (BioRad).

Equal amounts of protein were separated on $10 \%$ SDSpolyacrylamide gels, and following blocking, probed with relevant primary and HRP-conjugated secondary antibody. Membranes were processed using an enhanced chemiluminescence kit (ECL, Amersham), and visualized on Kodak BioMax MR-1 films.

\section{Cytotoxicity assay}

Cytotoxic activity measured by neutral red assay and the intensity of the color was read in ELISA reader at $570 \mathrm{~nm}$. All samples were run in five repeats. Statistical evaluation was carried out using factorial analysis (ANOVA), and Student's $t$-test. Values of $P<0.05$ were considered statistically significant.

\section{DNA fragmentation assay}

Cells were incubated with appropriate concentrations of taxol for $24-$ $72 \mathrm{~h}$, then lysed in a lysis buffer $(10 \mathrm{mM}$ Tris- $\mathrm{HCl}, \mathrm{pH} 7.4,10 \mathrm{mM}$ EDTA and $0.2 \%$ Triton X-100), and dissolved in TE buffer. DNA content was determined by spectrophotometry. Samples (10-20 $\mu \mathrm{g}$ DNA) were analyzed in $1 \%$ agarose gel in TBE buffer ( $45 \mathrm{mM}$ Trisborate, $1 \mathrm{mM}$ EDTA, $\mathrm{pH} 8.0$ ) for $3 \mathrm{~h}$ at $110 \mathrm{mV}$. Ethidium bromide was added to the gels $(0.5 \mathrm{~g} / \mathrm{ml})$ and running buffer $(0.1 \mu \mathrm{g} / \mathrm{ml})$. DNA fragments were visualized using ImageMaster VDS and photographed with FUJIFILM Thermal Imaging System FTI-500.

\section{Caspase-3 activity assay}

The assay was performed with the Caspase-3 Assay Kit containing also the inhibitor Ac-DEVD- CHO (Calbiochem). Briefly, the reaction mixture contained $10 \mu \mathrm{l}$ of supernatant, $80 \mu \mathrm{l}$ of assay buffer and $10 \mu \mathrm{l}$ of colorimetric substrate (Ac-DEVD-pNA). Upon cleavage by caspase3 , pNA produces a yellow color that can be measured at $405 \mathrm{~nm}$. When required, extracts were pre-incubated with caspase- 3 inhibitor Ac-DEVD-CHO (final concentration of $10 \mathrm{nM}$ ) for $10 \mathrm{~min}$ before the addition of the colorimetric substrate. Each experiment was repeated 4-6 times. The differences between the control and taxol-treated groups were considered statistically significant at $P<0.05$. In the text, representative experiments are shown.

\section{Acknowledgments}

This work has been supported by the Grant 5RO3 TW00927 (FIRCA $\mathrm{NIH}$ ), and by the Grants from the Israel Cancer Research Foundation and Israel Ministry of Sciences. R Seidman has been awarded a grant from the Keren Kayemet L'Israel Foundation. $\mathrm{R}$ Ofir has been awarded a grant from the Jewish Agency for Israel.

\section{References}

1. Wani MC, Taylor HL, Wall ME, Coggon P and McPhail AT (1971) Plant antitumor agents. VI. The isolation and structure of taxol, a novel antileukemic and antitumor agent from Taxus brevifolia. J. Am. Chem. Soc. 93: 2325-2327

2. Rowinsky EK and Donehower RD (1995) Paclitaxel (taxol). N. Engl. J. Med. 33: 1004-1014

3. Schiff PB, Fant J and Horwitz SB (1979) Promotion of microtubule assembly in vitro by Taxol. Nature 277: 665-667

4. Ding A, Sanchez E and Nathan CF (1993) Taxol shares the ability of bacterial lipopolysoccharide to induce tyrosine phosphorylation of microtubule-associated protein kinase. J. Immunol. 151: 5596-5602

5. Wolfson M, Yang CPH and Horwitz SB (1997) Taxol induces tyrosine phosphorylation of Shc and its association with Grb2 in murine RAW 264.7 cells. Int. J. Cancer 70: 248-252

6. Blagosklonny MV, Schulte T, Nguen P, Trepel J and Neckers LM (1996) Taxolinduced apoptosis and phosphorylation of bcl-2 protein involves c-Raf- 1 and represents a novel c-Raf-1 signal transduction pathway. Cancer Res. 56, 1851 1854

7. Fan W (1999) Possible mechanisms of paclitaxel-induced apoptosis. Biochem. Pharmacol. 57: 1215-1221

8. Tudor G, Aguilera A, Halverson DO, Laing ND and Sausville EA (2000) Susceptibility to drug-induced apoptosis correlates with differential modulation of Bad, Bcl-2 and Bcl-xL protein levels. Cell Death Differ. 7: 574-586

9. Haldar S, Chintapalli J, and Croce CM (1996) Taxol induces bcl-2 phosphorylation and death of prostate cancer cells. Cancer Res. 56: 1253-1255 
10. Ding A, Porteu F, Sanchez E and Nathan CF (1990) Shared actions of endotoxin and taxol on TNF receptors and TNF release. Science 248: $370-372$

11. Basu A and Hadar S (1998) Microtubule-damaging drugs triggered bcl-2 phosphorylation - requirement of phosphorylation on both serine- 70 and serine87 residues of bcl-2 protein. Int. J. Oncol. 13: 659-664

12. Blagosklonny MV, Schulte TW, Nguen P, Mimnaugh EG, Prepel J and Nechers L (1995) Taxol induction of p21-waf and p53 requires c-raf-1. Cancer Res. 55: $4623-4626$.

13. Thornberry AF and Lazenbik Y (1998) Caspases: enemies within. Science 281 $1312-1316$

14. Wolf BB, Schener M, Echeverri F and Green D (1999) Caspase-3 is the primary activator of apoptotic DNA fragmentation via DNA fragmentation factor-45/ inhibitor of caspase-activated DNase inactivation. J. Biol. Chem. 274: 30651 30656

15. Tang D and Kidd VJ (1998) Cleavage of DFF-45/ICAD by multiple caspases is essential for its function during apoptosis. J. Biol Chem. 273: 28549-28552

16. Walker PR, Leblanc J, Carson C, Ribecco M and Sikorska M (1999) Neither caspase-3 nor DNA fragmentation factor is required for high molecular weight DNA degradation in apoptosis. Ann. NY Acad. Sci. 887: 48-59

17. Huang Y, Ray S, Reed JC, Ibrado AM, Tang C, Nawabi A, and Bhalla K (1997) Estrogen increases intracellular p26Bcl-2 to p21Bax ratios and inhibits taxolinduced apoptosis of human breast cancer MCF-7 cells. Breast Cancer Res. Treat. 42: 73-81

18. Saleh A, Srinivasula SM, Acharya S, Fishel R and Alnemri ES (1999) Cytochrome $\mathrm{C}$ and dATP-mediated oligomerization of Apaf- 1 is a prerequisite for procaspase-9 activation J. Biol. Chem. 274: 17941-17945

19. Cain K, Brown DG, Langlais C and Cohen GM (1999) Caspase activation involves the formation of the apoptosome, a large (approximately $700 \mathrm{kDa}$ ) caspase-activating complex. J. Biol. Chem. 274: 22686-22692

20. Cecconi F, Alvarez-Bolado G, Meyer BI, Roth KA and Gruss P (1998) Apaf1 (CED-4 homolog) regulates programmed cell death in mammalian development. Cell 94: 727-737

21. Srinivasula SM, Ahmad M, Fernandes-Alnemri T and Alnemry ES (1998) Autoactivation of procaspase-9 by Apaf-1-mediated oligomerization. Mol. Cell 1: 949-957

22. Hakem RA, Hakem GS, Duncan JT, Henderson M, Woo MS, Soengas A, Elia J, de la Pompa D, Kagi W, Khoo J, Potter R, Yoshida SA, Kaufman SW, Lowe J, Penninger and Mak TW (1998) Differential requirement for caspase-9 in apoptotic pathways in vivo. Cell 94: 339-352

23. Ibrado AM, Kim CN and Bhalla K (1998) Temporal relationship of CDK1 activation and mitotic arrest result in cytosolic accumulation of cytochrome $\mathrm{C}$ and caspase-3 activity during Taxol-induced apoptosis of human AML HL-60 cells. Leukemia 12: 1930-1936
24. Weigel TL, Lotze MT, Kim PK, Amoscato AA, Luketich JD and Odoux C (2000) Paclitaxel-induced apoptosis in non-small cell lung cancer cell lines is associated with increased caspase-3 activity. J. Thorac. Cardiovasc. Surg. 119: $795-803$

25. Kagawa S, Gu J, Honda T, McDonnell TJ, Swisher SG, Roth JA and Fang B (2001) Deficiency of Caspase-3 in MCF7 Cells Blocks Bax-mediated Nuclear Fragmentation but not for Cell Death. Clin. Cancer Res. 7: 1474-1480

26. Walker PR, Leblanc J, Carson C, Ribecco M, Sikorska M (1999) Neither caspase-3 nor DNA fragmentation factor is required for high molecular weight DNA degradation in apoptosis. Ann. NY Acad. Sci. 887: 48-59

27. Perkins C, Kim CN, Fang G and Bhalla KN (1998) Overexpression of Apaf-1 promotes apoptosis of untreated and paclitaxel- or etoposide-treated HL-60 cells. Cancer Res. 58: 4561-4566

28. Montwani M, Delohery TM and Schwartz GK (1999) Sequential dependent enhancement of caspase activation and apoptosis by flavopiridol on paclitaxeltreated human gastric and breast cancer cells. Clin. Cancer Res. 5: 1876-1883

29. Goncalves A, Braguer D, Carles G, Andre N, Prevot C and Briand C (2000) Caspase-8 activation independent of CD95/CD95-L interaction during paclitaxel-induced apoptosis in human colon cancer cells (HT29-D4). Biochem. Pharmacol. 60: 1579-1584

30. Oyaizu H, Adachi Y, Taketani S, Tokunaga R, Fukuhara Sand lkehara S(1999) A crucial role of caspase 3 and caspase 8 in paclitaxel-induced apoptosis. Mol. Cell Biol. Res. Commun. 2: 36-41

31. Okani J-I and Rustgi AK (2001) Paclitaxel induces prolonged activation of the Ras/MEK/ERK pathway independently of activation of the programmed cell death machinery. J. Biol. Chem. 276: 19555-19564

32. Ling Y, Zhong Y and Perez-Soler R (2001) Disruption of cell adhesion and caspase-mediated proteolysis of beta- and gamma-catenins and APC protein in paclitaxel-induced apoptosis. Mol. Pharmacol. 59: 593-603

33. Joza N, Susin SA, Daugas E, Stanford WL, Cho SK, Li CY, Sasaki T, Elia AJ, Cheng HY, Ravagnan L, Ferri KF, Zamzami N, Wakeham A, Hakem R, Yoshida H, Kong YY, Mak TW, Zuniga-Pflucker JC, Kroemer G and Penninger JM (2001) Essential role of the mitochondrial apoptosis-inducing factor in programmed cell death. Nature 410: 549-554

34. Wolf BB, Goldstein JC, Stennicke HR, Beere H, Amarante-Mendes GP, Salvesen GS and Green DR (1999) Calpain functions in a caspase-independent manner to promote apoptosis-like events during platelet activation. Blood 94: $1683-1692$ 